\title{
DE MALAS PRONTAS PARA A ANTÁRTICA
}

\author{
Suitcases packed to Antarctica
}

Maletas empacadas para Antártida

\author{
Carina Petsch* \\ Rafaela Mattos Costa** \\ Luiz Felipe Velho *** \\ Kátia Kellem da Rosa****
}

\begin{abstract}
*Professora do Departamento de Geociências/UFSM - carinapetsch@gmail.com
${ }^{* *}$ Graduanda em Geografia/UFRGS - raffaellamattos@hotmail.com

*** Professor do IFRS - Campus Porto Alegre - luiz.velho@poa.ifrs.edu.br

**** Professora do Departamento de Geografia/UFRGS - katiakellem@gmail.com
\end{abstract}

Recebido em 20/10/2019. Aceito para publicação em 20/10/2019.

Versão online publicada em 10/11/2019 (http://seer.ufrgs.br/paraonde)

\section{Resumo:}

Quando se aborda o tema "Antártica", a grande dificuldade é "aproximar" o aluno desse ambiente e permitir sua inserção, de modo que possa usar o conhecimento de filmes, jornais e mídia online para construir suas reflexões sobre o continente. Assim, o objetivo desta pesquisa é abordar alguns conceitos e características do continente antártico por meio de uma oficina lúdica. O método consistiu em quatro etapas: na primeira os alunos foram convidados a compor uma possível "mala" para levar à Antártica, colando numa folha, itens que julgaram importantes para uso nesse ambiente; no segundo momento, os mediadores da oficina realizaram uma discussão sobre quais itens eram realmente utilizados na Antártica no que tange a: transporte, alimentação, higiene pessoal, moradia e pesquisa científica; na terceira e quarta fases, após a discussão, os alunos puderam vestir roupas da expedição e adentrar nas barracas para "sentir" o continente. Os alunos se demonstraram empolgados e até os mais desinteressados participaram. Os resultados mostram que os alunos retratam a Antártica igual ao que é visto em filmes, trazendo elementos da paisagem do pólo norte, com iglus, inuits, caça e pesca de animais para sobrevivência. Outro fator que merece destaque, é que tanto nos aspectos de comunicação quanto transporte, os alunos julgam a Antártica como um continente inóspito.

Palavras-chave: Antártica.Oficinas lúdicas.Geografia polar.

\begin{abstract}
:
When we talk about the "Antarctic" theme, the great difficulty is to "bring" the student closer to this environment and allow their insertion, so that they can use the knowledge of movies, newspapers and online media to build their reflections on the continent. Thus, the aim of this research is to address some concepts and characteristics of the Antarctic continent through a playful workshop. The method consisted of four steps: in the first one the students were asked to compose a possible "suitcase" to take to Antarctica, by sticking on a sheet, items that they considered important for use in this environment; Secondly, the workshop's mediators held a discussion about which items were actually used in Antarctica with regard to: transportation, food, personal hygiene, housing, and scientific research; In the third and fourth phases, after the discussion, the students were able to wear expedition clothes and enter the tents to "feel" the continent. The students were excited and even the most disinterested participated. The results show that students portray Antarctica as seen in movies, bringing elements of the North Pole landscape with igloos, Inuits, hunting and fishing for survival. Another factor is that in terms of communication and transportation, students
\end{abstract}


regard Antarctica as an inhospitable continent.

Key-words: Antarctica. Ludic workshops. Polar geography.

\begin{abstract}
Resumen:
Al abordar el tema de la "Antártida", la gran dificultad es "acercar" al estudiante a este entorno y permitir su inserción, para que pueda usar el conocimiento de películas, periódicos y medios en línea para construir sus reflexiones en el continente. Por lo tanto, el objetivo de esta investigación es abordar algunos conceptos y características del continente antártico a través de un taller lúdico. El método consistió en cuatro pasos: en el primero, se pidió a los estudiantes que compusieran una posible "maleta" para llevar a la Antártida, pegando en una hoja, elementos que consideraban importantes para usar en este entorno; En segundo lugar, los mediadores del taller mantuvieron un debate sobre qué artículos se utilizaron realmente en la Antártida con respecto a: transporte, alimentos, higiene personal, vivienda e investigación científica; En la tercera y cuarta fase, después de la discusión, los estudiantes pudieron usar ropa de expedición y entrar a las carpas para "sentir" el continente. Los estudiantes estaban entusiasmados e incluso los más desinteresadosparticiparon. Los resultados muestran que los estudiantes retratan la Antártida como se ve en las películas, trayendo elementos del paisaje del Polo Norte con iglúes, inuits, caza y pesca para sobrevivir. Otro factor notable es que, tanto en términos de comunicación como de transporte, los estudiantes consideran a la Antártida como un continente inhóspito.
\end{abstract}

Palabras-clave: Antartida. Taller ludico. Geografía polar.

\title{
1. Introdução
}

O Ensino de Geografia necessita de contextualização e exemplificaçãodos conceitos no campo do local, do ambiente e da vivência dos alunos, especialmente na Educação Básica. Callai (2009)e Cavalcanti (2005) ressaltam que, a partir do cotidiano dos alunos, é possível efetivar os conceitos e processos num espaço concreto aparente e visível, permitindo, ao aluno, um aprendizado que faz parte da própria vida. Contudo, ao estudar os continentes, o Antártico é aquele que acaba por ser o mais distante, sendo que o conhecimento sobre essa área ocorre mais pelos aspectos de informação, vivência e construção abstrata do ambiente. Conforme Callai (2009), a construção dos conceitos ocorre pela prática diária, pela observação, pelas experiências, pelo fazer (CALLAI, 2009). Assim, como pode-se abordar questões antárticas com alunos de um país sem neve? E mais, quais são os materiais disponíveis na escola, como o livro didático, e qual a abordagem que esses materiais dão à Geografia das regiões polares?

Silveira et al. (2014) apontam que poucos são os autores que, nos livros didáticos, abordam o continente antártico. Os autores ainda afirmam que os materiais analisadosbaseiam-se em mitos, informações midiáticas nada confiáveis eem dados desatualizados, das décadas de 1960 e de 1970, sobre a Antártica. No caso específico deste estudo,Silveira et al. (2014)avaliaram como eram apresentadas informações referentes ao relevo. Dos 25 livros didáticos analisados, somente nove possuíam alguma informação sobre Antártica e, desses, apenas sete continham dados sobre relevo. No entanto, apenas dois livros apresentaram um modelo de elevação do continente, constando, nos demais materiais didáticos, somente a informação sobre o ponto mais alto da Antártica (SILVEIRA et al., 2014).

Visto que os livros não são os materiaismais adequados para o ensino de geografia das regiões polares, torna-se imprescindível criar e desenvolver outras estratégias

ParaOnde!?, Porto Alegre, v.12 n.2, p.180-192, 2019.http://seer.ufrgs.br/paraonde Edição Especial - III Colóquio de Pesquisadores em Geografia Física Ensino de Geografia 
didáticas. Apesar de existiremdiferentes formas de realizara abordagem das questões antárticas com os alunos, as oficinas lúdicas e jogos, que trazem vídeos fotografias e curiosidades sobre o assunto, têm mostrado resultados satisfatórios. Petsch et al. (2017) demonstram o potencial de uso de técnicas projetivas para se avaliar o que o aluno conhece sobre a Antártica, principalmente por meio de desenhos. De acordo com Sacristán (2002), a ação educativa escolar se torna válida ao explorar com os alunos o desconhecido que, por meio das experiências pessoais e de vivência cotidiana não seria possível adquirir.

Assim, espera-se que o conhecimento sobre o continente antártico, já que não pode ser feito de maneira direta, seja construídopelo uso de fotografias, vídeos e jogos ou oficinas lúdicas. Segundo Jimenez e Gaite (1995, p. 83):

jogos de simulação são para a Geografia, como as experiências de laboratório para as ciências experimentais. O Geógrafo não consegue reproduzir no laboratório os fatos e fenômenos que estuda, reproduz recorrendo à simulação e ao jogo. Isto permite abordar com simplicidade certos temas de caráter complexo.

Por meio dos jogos, a criança aprende a orientar-se no espaço e no tempo, a desempenhar os papéis necessários para as futuras etapas da sua vida, a saber, perder e ganhar (BROTTO, 1999), e também pode "viajar", saindo da sua realidade cotidiana e se imaginando em outros ambientes, descobrindo a geografia polar usando sua criatividade, suas ideias-âncora e informações trazidas pelo professor.

Atualmente, é comum o incentivo a ações pedagógicas que explorem espaços e atividades contextualizadas, mesmo sabendo que nem sempre é tarefa fácil. Assim, esse artigo tem por objetivo apresentar o relato de um trabalho ministrado na forma de oficina lúdica sobre uma temática pouco comum, que é a Antártica, onde foram abordados os temas: transporte, comunicação, alimentação, sobrevivência e pesquisa científica.

\section{Contextualização teórica e planejamento da oficina}

A oficina lúdica "Fazendo as malas para a Antártica" objetivou estimular a reflexão dos estudantes sobre a vivência dos pesquisadores e o próprio ambiente antártico a partir de uma situação problema.Por ser uma atividade não curricular e que tem ocorrência única em uma turma, deve-se atentar para um embasamento teórico condizente com tal prática. Dada essa consideração, é importante pensar na contextualização como forma de otimizar o processo de apresentação do tema proposto, visando uma aproximação entre os alunos e o conteúdo.

Cabe apontar que a ideia de contextualização é um elemento forte nessa ação pedagógica, como abordado na introdução. A contextualização tem a finalidade de proporcionar maior espaço de aprendizagem aos estudantes de uma temática muito distante da comunidade escolar atingida por esta ação educativa. Assim, para que fosse possível buscar a atenção do público alvo de forma instantânea, personalidades populares no cotidiano pré-adolescente e adolescente foram escolhidas, bem como elementos e vocabulário próximos da realidade dos oficinandos. Nessa etapa, a teoria da aprendizagem significativa foi utilizada como arcabouço para a construção de uma atividade única e que fosse capaz de adicionar informações aos conhecimentos já consolidados no cognitivo dos participantes.

ParaOnde!?, Porto Alegre, v.12 n.2, p.180-192, 2019.http://seer.ufrgs.br/paraonde Edição Especial - III Colóquio de Pesquisadores em Geografia Física Ensino de Geografia 
$\mathrm{Na}$ aprendizagem significativa, proposta por Ausubel, para que novos conhecimentos sejam aprendidos é necessário pontos de ancoragem, sendo esses conhecimentos prévios chamados de subsunçores (MOREIRA, 2017). Os conhecimentos subsunçores são categorizados e hierarquizados, ou seja, eles são a base para um novo conhecimento aprendido e, ao aumentar o conhecimento nessa área da estrutura cognitiva, o ponto de ancoragem aumenta, dando maiores subsídios para a aprendizagem de novos conceitos (MOREIRA, 2017).

Petsch et al. (2017) mostram que os alunos do ensino básico possuem informações a respeito de ambientes glaciais a partir, principalmente, de filmes de animação. Assim, pode-se considerar que há um subsunçor que pode ser ampliado ou modificado. Não obstante, informações sobre o cotidiano e a sobrevivência das pessoas também são subsunçores, podendo ser utilizados na atividade.

Partindo-se desses subsunçores pode-se elaborar uma atividade potencialmente significativa, capaz de criar ligações entre esses conhecimentos prévios (MOREIRA, 2017). Conforme Moreira (2017), uma das formas de trabalhar a aprendizagem significativa é propondo problemas que exijam a mobilização de conhecimentos em diferentes realidades.

Ainda sobre a aproximação de novas informações/conteúdos às realidades das crianças e jovens, Perrenoud (2000, p. 28) traz importantes reflexões acerca do "trabalhar a partir das concepções dos alunos, dialogar com eles, fazer com que sejam avaliadas para aproximá-las dos conhecimentos científicos a serem ensinados". Na questão do ensinar utilizando as representações dos alunos, o mesmo autor destaca que a didática, ao professor

Ajuda-o a fundamentar-se nas representações prévias dos alunos, sem se fechar nelas, a encontrar um ponto de entrada em seu sistema cognitivo [...] para levá-los a restabelecerem o equilíbrio, incorporando novos elementos às representações existentes, reorganizando-as se necessário (PERRENOUD, 2000, P. 28)

É importante ressaltar a importância de algumas concepções de Paulo Freire que norteiam essa ação pedagógica, como o diálogo entre todos os agentes; o papel e perfil do oficineiro - que é um educador -; e o objetivo central, que é um educando cidadão.Para Freire (1996), o diálogo é essencial em qualquer relação e, em especial, quando trata-se de trocas de experiências, de espaços de aprendizagem ou de momentos de interação. Ainda, conforme Freire (1996), o óbvio sempre precisa ser dito, pois o outro não sabe o que eu estou pensando ou o que já vivi. Essa perspectiva de atuação docente é importante para que seja possível manter uma conversa, ou atividade, ou jogo, visto que é fundamental a compreensão do que se deseja abordar e quais os caminhos para que a abordagem se efetive.A mesma perspectiva se aplica ao processo de aprendizagem, pois quando tratamos de conceitos de uma disciplina/área do conhecimentonão é primordial que os alunos repitam frases prontas de definição de conceitos, mas é imprescindível que o educando consiga, com seus conjuntos de informações, compreender o conceito abordado e queseja capaz de explicá-lo com suas palavras,relatando sua construção. Assim, o diálogo é basilar em atividades contextualizadas, onde um único conceito pode estar em diferentes cenários propostos, só ou integrado a outros conceitos, o que exige mobilização de conhecimentos, tornando rica e diversificada a "vivência" do conceito trabalhado.

ParaOnde!?, Porto Alegre, v.12 n.2, p.180-192, 2019.http://seer.ufrgs.br/paraonde Edição Especial - III Colóquio de Pesquisadores em Geografia Física Ensino de Geografia 
No processo de realização dessa oficina, o oficineiro não tem controle sobre as escolhasdo educando. Assim, o diálogo durante a atividade, e posterior a sua realização, são fundamentais para que todas as etapas sejam cumpridas e os conhecimentos ampliados, tanto dos alunos a respeito da Antártica quanto do oficineiro a respeito da realidade escolar e dos aspectos culturais locais que podem ser utilizados na aproximação entre os elementos antárticos e o cotidiano dos jovens.

O educador é a pessoa que pensa a oficina, planeja, faz, modifica, molda, adapta ao público e vivência os possíveis desenvolvimentos e aprendizados que nessa se desfruta, tendo como objetivo central proporcionar o desenvolvimento do cidadão. $O$ educador é um agente, não necessariamente docente, que proporciona um desenvolvimento que pode se tornar uma aprendizagem. Assim, ele tem um plano de ação, que pode ser do tipo modalidade de ensino ou, como aponta Piaget (1978), um fazer e compreender entre pares. O que seriam os pares? Os educandos estão criando a oficina através das atividades propostas pelo educador, mas esse é também educando, já que depende da ação dos demais para conduzir a oficina.

O oficineiro, na atividade proposta, não exerce o papel de professor, conceitualmentemais controladora e imperativa. Isso porquepor trás daatuação de um professor, em sala de aula, existe toda uma organização curricular da escola, que, muitas vezes, engessa atividades de oficina. Dessa forma, o conceito de educador fica mais adequado pela liberdade de planejamento e expressão da temática que não é conteúdo específico de nenhuma disciplina, isto é, tem caráter interdisciplinar. Por ser interdisciplinar, o tema abordado pode ser conduzido por mais de um educador, caso estejam interessados em dialogar entre si e com os educandos.

O conceito de cidadão é aquele que pensa criticamente suas ações e dos demais, é a pessoa que consegue perceber diferentes olhares e juízos de valor sobre a mesma situação, por exemplo. Além disso, Freire (1996) destaca que cidadão sabe seus direitos e deveres e luta por eles conscientemente. Transportando essa ideia a um espaço de oficina, tem-se que a liberdade de experimentar todas as possibilidades das atividades propostas e ter o espaço de reflexão com as suas associações pode formar cidadãos que poderão transformar seus conhecimentos sobre Antártica em ações positivas de cuidados ao meio ambiente, pelo simples fato de entender que, na Terra, há várias conexões entre os diferentes compartimentos do ambiente.

\section{Planejamento e execução da oficina}

Lambros (2002) relataque é preciso criar uma situação com cenário ouproblema, ou seja, com a criação de situações que instigam, motivam e familiarizam os alunos com a temática que será estudada. Sendo assim, o processo de ensino aprendizagem ocorreu de acordo com quatro etapas (Figura 1).

ParaOnde!?, Porto Alegre, v.12 n.2, p.180-192, 2019.http://seer.ufrgs.br/paraonde Edição Especial - III Colóquio de Pesquisadores em Geografia Física Ensino de Geografia 
Figura 1 - Fluxo metodológico adotado para a oficina. A partir de uma situação problema os alunos foram instigados a refletirem sobre aspectos e características do continente antártico.

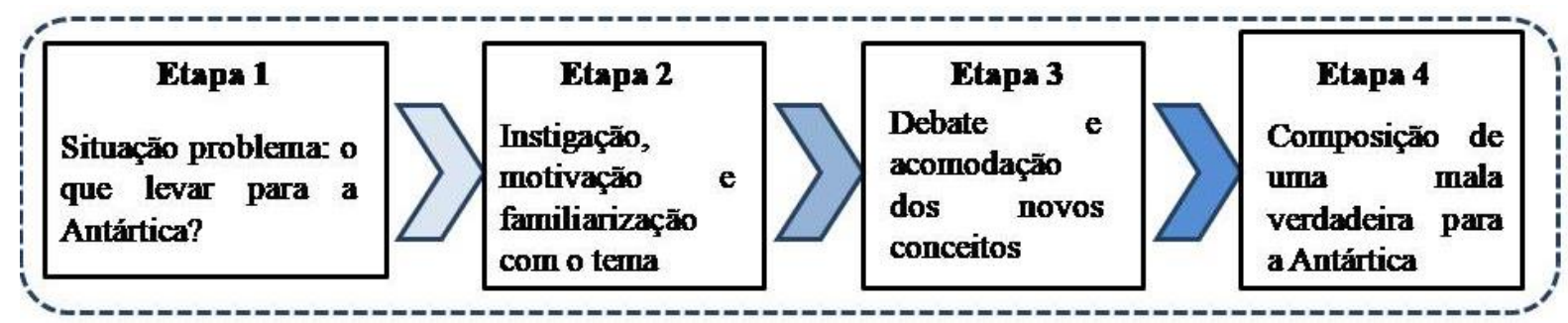

Fonte: autores

$\mathrm{Na}$ etapa 1, os educandos foram convidados a fazer uma possível mala que seria levada para a Antártica, com itens de alimentação, pesquisa, vestuário, transporte, permanência na Antártica. Todos os itens oferecidos, aos estudantes, para composição da mala, foram recortados e deixados sobre as mesas, enquanto eles circularam sem interferência do oficineiro, e escolheram os itens que julgaram ser indispensáveis para suas malas.

A escolha dos objetos a serem apresentados para os alunosbaseou-se em itens que são primordiais para a realização de um trabalho de campo, bem como sobreviver, durante no continente antártico. Optou-se por itens que são comumente vistos em filmes, em documentários e na internet. Dentro da temática alimentação, por exemplo, foramescolhidas uma figura de lenha e uma de vara de pesca. Essa escolha deu-se pela intenção de verificar a possível associação que os educandos poderiam realizar entre Antártica e cultura de povos do Ártico, que pescam para sua sobrevivência. Na tabela 1, há a descrição de todos os itens selecionados para a composição das malas e,na figura 2, há a representação de alguns dos itens disponibilizados aos educandos.

Tabela 1 - Objetos selecionados para a oficina

\begin{tabular}{l|l}
\hline Categoria & Objetos \\
\hline Alimentos & comidas perecíveis, enlatados e "comida de astronauta" \\
\hline Vestimentas & casacos, óculos, calça e camisetas \\
\hline Moradia & barraca e iglus \\
\hline Comunicação & rádios, notebooks e celular \\
\hline Transporte & avião e navio \\
\hline Material científico & $\begin{array}{l}\text { GPS (Global Position System), lupa, martelo geológico, } \\
\text { drone, pá e caderno de anotação }\end{array}$ \\
\hline Material de lazer & violão, livros e bola de futebol. \\
\hline Material de sobrevivência & água e papel higiênico \\
\hline
\end{tabular}

Fonte: autores

Depois de distribuídos os itens sobre as mesas, os alunos receberam uma folha com a foto uma personalidade impressa (Figura 3). Nessa folha, os educandos deveriam colar os itens que eles julgassem fundamentais para que a personalidade da folha pudesse viajar para a Antártica.Trata-se de uma atividade lúdica, que a partir de um problema, levou os alunos a refletirem sobre a Antártica (etapa 2).

ParaOnde!?, Porto Alegre, v.12 n.2, p.180-192, 2019.http://seer.ufrgs.br/paraonde Edição Especial - III Colóquio de Pesquisadores em Geografia Física Ensino de Geografia 
Foram escolhidas celebridades que fazem parte do cotidiano do educando (Demi Lovato, Anitta, Justin Bieber e MC Guimé), visando tornar a oficina mais próxima das vivências dos participantes. Todavia, seria interessante substituir a figura da celebridade pela fotografia dos alunos, na tentativa de tornar essa suposta viagem mais real.

Figura 2 - Exemplos de objetos que foram oferecidos para os alunos comporem suas malas.

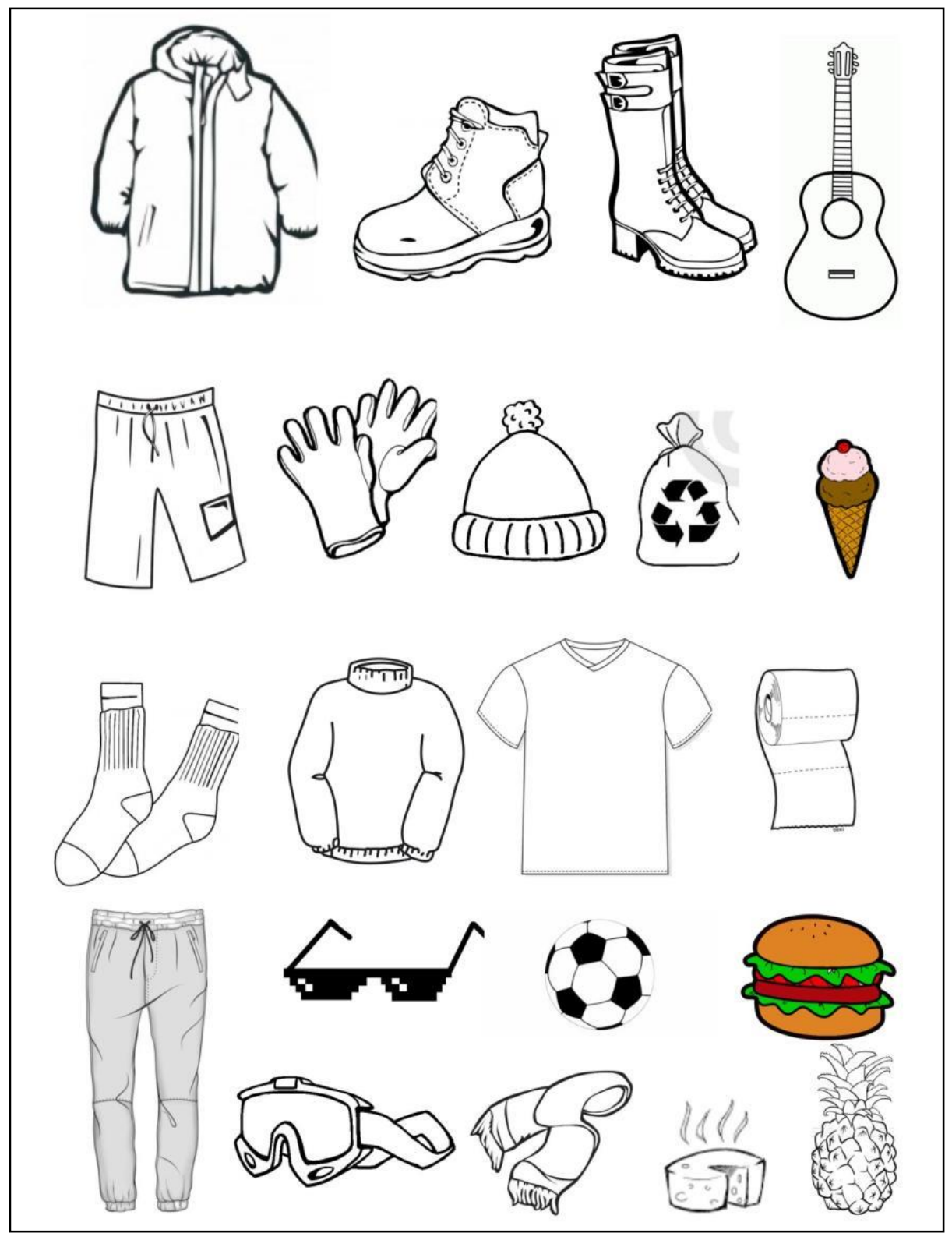

Fonte: autores 
Figura 3 - Exemplo de mala que deveria ser feita para a personalidade Justin Bieber ir até a Antártica.

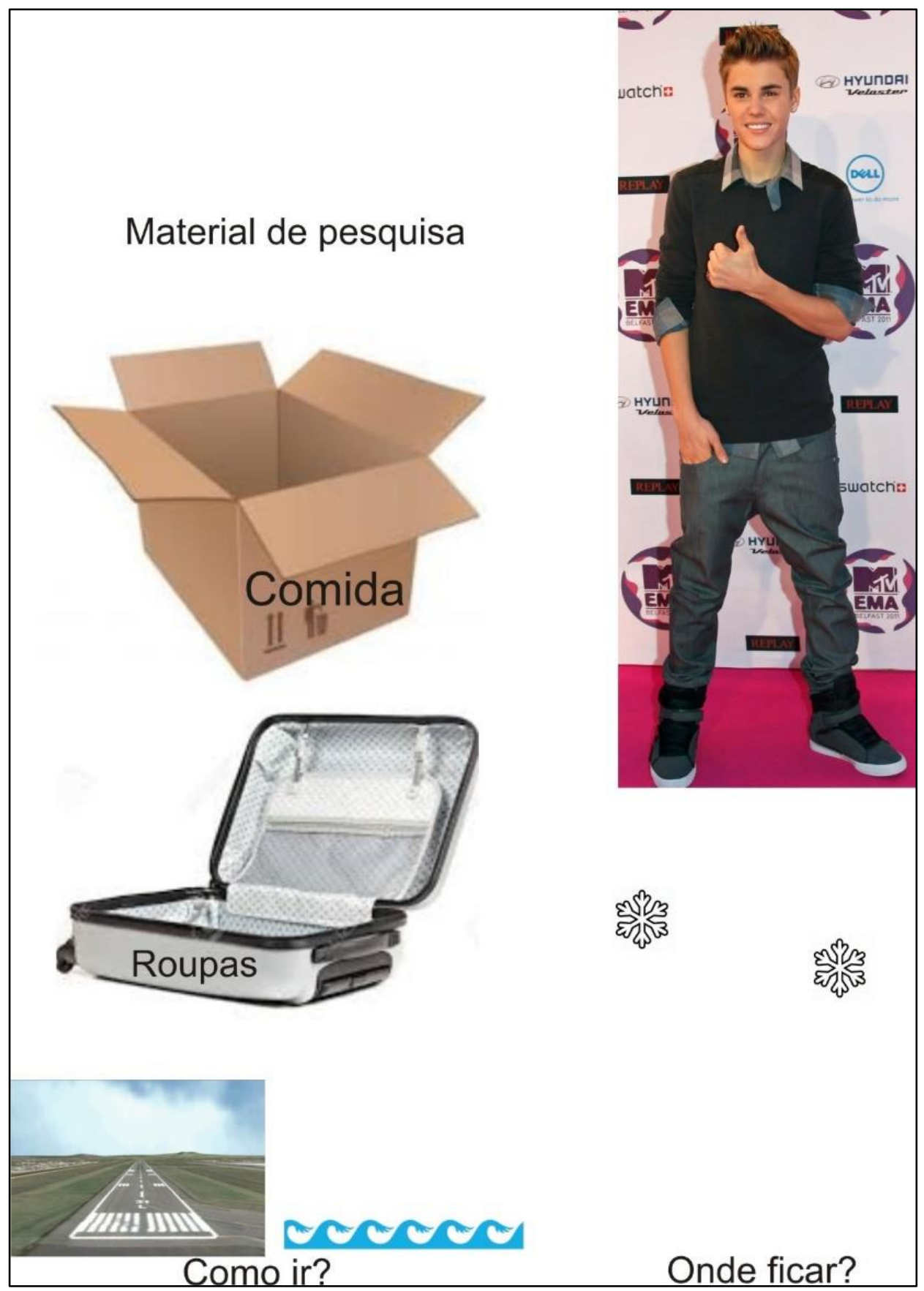

\section{Fonte: autores}

Após a colagem dos itens nas folhas, correspondentes às malas de cada celebridade, iniciou-se aEtapa 3. Nesta etapa foi realizado um debate sobre a escolha dositens, os levando a refletir sobre a verossimilhançade suas escolhas. Durante as explicações dos educandos, o educadorbuscou saber de onde essas informações eram provenientes, se de filmes, de documentários, dainternet, ou de outra fonte. Assim, a partir da apresentação de vídeos e fotografias, os alunos reconstruíram seu conhecimento acerca da Antártica.

ParaOnde!?, Porto Alegre, v.12 n.2, p.180-192, 2019.http://seer.ufrgs.br/paraonde Edição Especial - III Colóquio de Pesquisadores em Geografia Física Ensino de Geografia 
Por fim, na Etapa 4, foi realizadaa montagem de uma mala verdadeira, com itens concretos, usados por pesquisadores. Nessa atividade, os alunos puderam experimentar vestimentas utilizadas em trabalhos de campo na Antártica, bem como objetos de pesquisa. Assim, conseguiram transpor o lúdico para objetos reais e reacomodar as novas informações e experiências sobre o tema em questão.

\section{Resultados e discussões}

A seguir, apresenta-se algumas transcrições de ações e reações do educador e dos educandos visando analisar e perceber como se deu o desenvolvimento da oficina e seus aprendizados.

Nessa oficina, o maior mito foi sobre o local de permanência, dos pesquisadores, na Antártica. Evidência disso é que $50 \%$ dos grupos de alunos indicaram o iglu como moradia antártica. Isso mostra que os alunos confundem a cultura inuit, população tradicional do Hemisfério Norte,com aacomodaçãoque os pesquisadores teriam no ambiente antártico. Isso se deve, conforme as conversas realizadas na Etapa 3 da oficina, as imagens que são reproduzidas nos filmes, que geralmente retratam as áreas de neve como aquelas de cultura inuit, com pesca, moradia em iglus, ursos polares e lobos. A Antártica, infelizmente, é retratada frequentemente em filmes de terror, com criaturas fantásticas ou então em documentários que pouco são vistos pelos estudantes. Ainda sobre moradia, somente $25 \%$ consideram a presença de estações científicas e $15 \%$ incluíram barracas e sacos de dormir. Muitos pesquisadores ficam hospedados em bases científicas, porém quando a área de estudo é distante de uma base, os pesquisadores ficam acampados.

Em relação à comida, somente 1 grupo inseriu "comida de astronauta" (Figura 4), ficando a maioria das malas com enlatados, frutas, leite, pão, pipoca, chocolate e frango.Metade dos grupos colocou hambúrguer, e 15\% incluiu água na mala. A maioria dos educandos, quando questionados na terceiraetapa da oficina, afirmou que a água não é necessária já que pode ser usada a neve antártica. Cerca de $40 \%$ colocou na mala lenha, visando cozinhar peixes e até pinguins.Incluíram varas de pesca $20 \%$ deles, enquanto $10 \%$ dos grupos inseriram um fogão e $20 \%$ adicionaram um botijão. $\mathrm{Na}$ realidade os pesquisadores, quando acampados, montam uma barraca para cozinha onde os alimentos são cozidos em um fogão agás. Não é utilizada lenha e todos os alimentos são levados do Brasil. A alimentação consiste em alimentos enlatados, mas também se leva água, macarrão, arroz, bolachas, entre outros. Por fim, salienta-se que a Antártica é um continente somente com fins científicos e a caça e a pesca são proibidas.

Quanto ao meio de transporte, 70\% consideraram o avião (Figura 4), 40\% inseriram navios e alguns adicionaram ambos. Ressalta-se que, ao mesmo tempo em que consideram o avião como meio de transporte, não acreditam que haja aeroportos na Antártica. Esse resultado é diferente de outras oficinas realizadas abordando transporte no continente, já que os alunos, na sua maioria, acabam considerando o navio como único meio de transporte. Na Antártica, existem algumas pistas de pouso, sendo algumas na neve e outras nas áreas livres de gelo no verão.

ParaOnde!?, Porto Alegre, v.12 n.2, p.180-192, 2019.http://seer.ufrgs.br/paraonde Edição Especial - III Colóquio de Pesquisadores em Geografia Física Ensino de Geografia 
Figura 4 - Algumas malas elaboradas pelos alunos. É possível notar a presença de iglus e lenhas que são itens frequentes em filmes sobre o assunto; e também verifica-se a presença de GPS, gerador de energia elétrica e pás para retirada de neve, objetos necessários para o trabalho de campo.

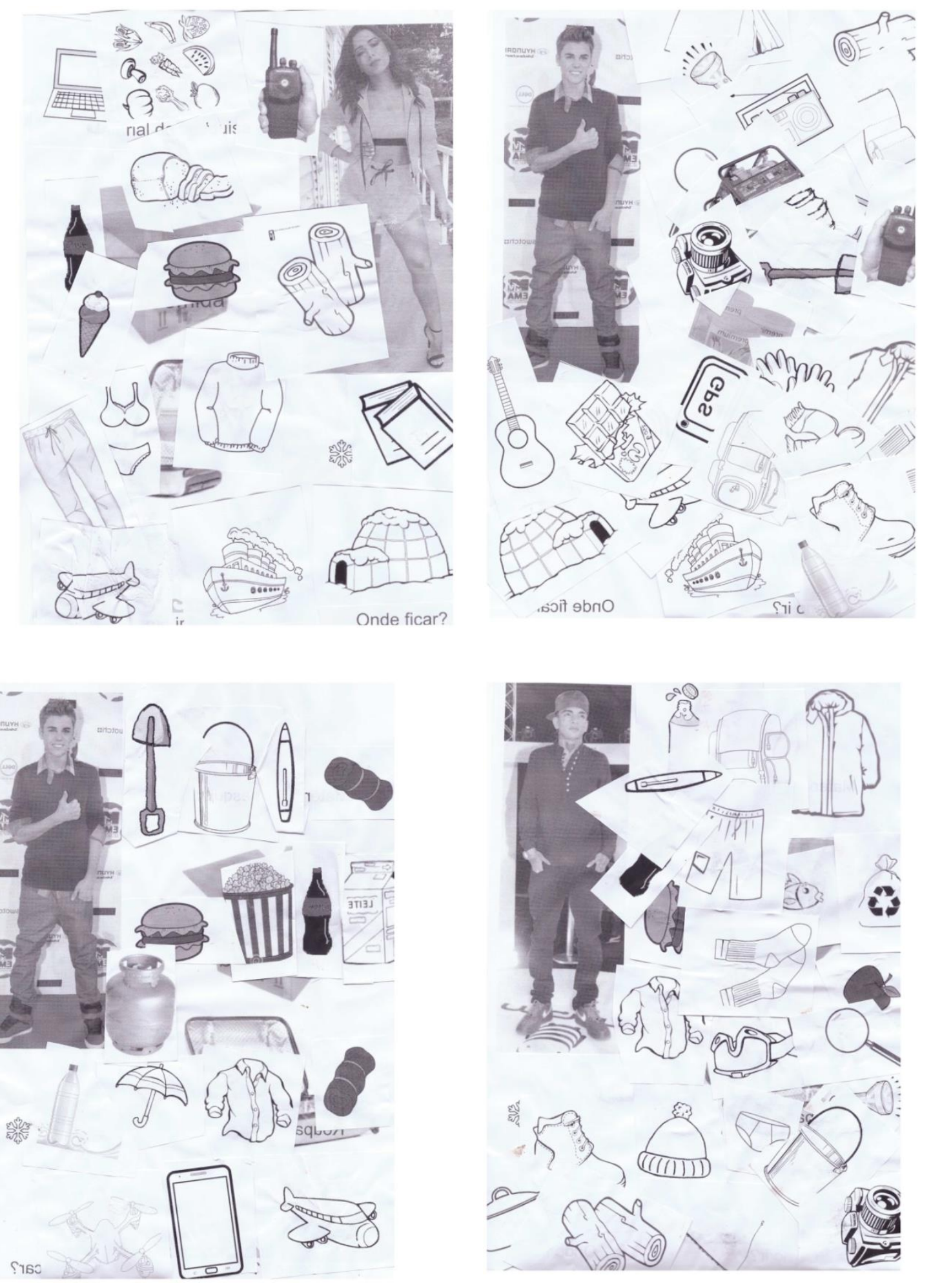

Fonte: autores

ParaOnde!?, Porto Alegre, v.12 n.2, p.180-192, 2019.http://seer.ufrgs.br/paraonde Edição Especial - III Colóquio de Pesquisadores em Geografia Física Ensino de Geografia 
Cerca de $45 \%$ incluíram remédios, julgando ser importante para possíveis resfriados nesse ambiente. Na realidade, sempre deve-se levar remédios, mas principalmente para queimaduras na pele ocasionadas pelo frio ou acidentes em caso de queda em fendas no gelo. Aproximadamente $60 \%$ dos grupos inseriu rádios na sua mala e somente 1 grupo colocou um celular. A comunicação é feita por rádios entre os pesquisadores e a comunicação com os navios brasileiros ou com a família é feita por celulares com conexão por satélite. Nas bases científicas muitas vezes tem-se acesso à internet. Contudo, na imaginação dos alunos a Antártica é um ambiente extremamente inóspito, onde os pesquisadores seriam desbravadores, ou seja, ter um sinal de internet seria impossível.

Quanto aos materiais de pesquisa, os mais populares foram: com $40 \%$, o drone; $30 \%$, o martelo geológico; $25 \%$, a câmera; e 15\%, o GPS. Porém, infelizmente, a maioria dos alunos não considera haver pesquisa científica feita por brasileiros na Antártica. Ou seja, têm dificuldade de compreender a importância desse continente para o sistema climático global e sua interferência no Brasil.

$\mathrm{Na}$ Etapa 4, os educandos foram convidados a se aproximarem de um espaço onde estavam expostos os objetos e roupas utilizadas por pesquisadores, em trabalhos antárticos. Foi possível experimentar botas, casacos, calças, toucas, óculos, entre outros objetos. A mala utilizada para carregar todos os objetos também era a mesma utilizada pelos pesquisadores. Todos os participantes ficaram animados ao tocar as roupas e objetos e expressavam, verbalmente, o quando as sensações eram próximas ou distantes da realidade deles. Após experimentarem os objetos, todos acompanharam a montagem da mala.

\section{Considerações finais}

A oficina demonstrou bons resultados visto que mobilizou quase todos alunos a identificar osobjetos que comporiam suas malas. A atividade lúdica fomentou, de forma indireta, a procura dos alunos por uma solução para a situação apresentada, e os mesmos se mobilizaram e demonstraram seu conhecimento prévio sobre a Antártica de uma forma mais prazerosa e atrativa. Nas aulas de Geografia, assim como nas demais disciplinas, é importante pensar em novas estratégias metodológicas que incentivem os alunos a viver diferentes paisagens e a se transportarem para ambientes tão distantes de suas realidades.

Ressalta-se que o conhecimento dos alunos está muito ligado aos filmes, que trazem na sua maioria aspectos culturais e característicos do Hemisfério Norte, como o povo inuit, iglus, ursos,lobos, caça e pesca para sua sobrevivência. A Antártica é compreendida, pelos educandos, da mesma forma que o pólo Norte. Isso se revela pela inclusão de itens como iglus, lenha e varas de pescar, nas malas. Nesse sentido, os educandos acreditam que os pesquisadores são desbravadores num continente inóspito, e muitos ficaram surpresos com o fato de haver bases científicas.

Quando trata-se de comunicação e transporte, nota-se que há uma descontinuidade na percepção dos processos. No caso da comunicação, eles relatam que o rádio é o instrumento utilizado na Antártica, mas não compreendem o funcionamento do

ParaOnde!?, Porto Alegre, v.12 n.2, p.180-192, 2019.http://seer.ufrgs.br/paraonde Edição Especial - III Colóquio de Pesquisadores em Geografia Física Ensino de Geografia 
aparelho. De outro lado, eles acreditam que não há sinal de celular, tão pouco de internet, mas não sabem o motivo pelo qual não teria sinal no continente. Sobre transporte, o avião foi amplamente citado pelos participantes, mas eles não acreditam ter pista de pouso, isto é, o avião é uma forma de chegar a um lugar inóspito, mas não se sabe como ele pode pousar.

A oficina contribuiu para fazer com que esses jovens pudessem refletir e descobrir novas informações sobre o continente antártico, a partir de conhecimentos prévios que eles já possuíam. E a etapa de experimentação das roupas e objetos foi fundamental para a compreensão dos temas abordados.Acredita-se que o fato de minimamente sentirem o calor dos casacos e peso das botas aproximou os participantes euma Antártica "quase real".

\section{Referências}

BARBOSA, J. L. Geografia e cinema: em busca de aproximações e do inesperado. In: CARLOS, A. F, A. A Geografia na sala de aula. 5. ed. São Paulo: Contexto, 2003, p. 109-133.

BROTTO, F. O. Jogos cooperativos: se o importante é competir, o fundamental é cooperar. Santos-SP: Re-Novada, 1999.

CALLAI, H. C. Estudar o lugar para compreender o mundo. In: Ensino de geografia: práticas e textualizações no cotidiano. Porto Alegre: Mediação, 2009.

CASTROGIOVANNI, A. C. Apreensão e compreensão do espaço geográfico. In: Ensino de geografia: práticas e textualizações no cotidiano. Porto Alegre: Mediação, 2009.

COSTELLA, R. Z. O significado da construção do conhecimento geográfico gerado por vivências e por representações espaciais. Tese de doutorado. UFRGS, Porto Alegre, 2008.

FREIRE, P. Pedagogia da Autonomia: saberes necessários à prática educativa. São Paulo: Paz e Terra, 1996.

GIASANTI, R. Atividades para a aula de geografia: Ensino fundamental, 6ำ ao 9o ano. 1. ed. São Paulo: Nova Espiral, 2009.

JIMENEZ, A.; GAITE, M de J, Enseñar Geografia: de la teoria a la práctica. Colección Espacios y Sociedades, n. 3, Madri: Editorial Síntesis, S.A., 1995.

LAMBROS, A., Problem based learning in k-8 classrooms- a teacher's guide to implementation. Corwin Press, California, 2002.

MOREIRA, M. A. Teorias de Aprendizagem. São Paulo: E.P.U., 2ed, 2017.

ParaOnde!?, Porto Alegre, v.12 n.2, p.180-192, 2019.http://seer.ufrgs.br/paraonde Edição Especial - III Colóquio de Pesquisadores em Geografia Física Ensino de Geografia 
PERRENOUD, P. 10 novas competências para ensinar. Porto Alegre: Artmed, 2000.

PETSCH, C.; SILVEIRA, P. C.; HOLGADO, F. L.; ROSA, K. K.; VELHO, L. F.; SIMOES, J. C. Sentindo os pólos: experiências sensoriais para o aprendizado de Antártica e Ártico. In: PESSOA, V. L. S.; RUCKERT, A. A.; RAMIRES, J. C. L. Pesquisa Qualitativa: Aplicações em Geografia. 2017. Disponível em https://lume.ufrgs.br/handle/10183/172820

PIAGET, J. Biologia e Conhecimento. 2ª Ed. Vozes: Petrópolis, 1978.

SILVEIRA, P. da C.; PETSCH, C.; SIMÕES, J. C. Entre os altos e baixos do livro didático: a Antártica não é plana. Revista Geonorte, Edição Especial 4, v.10, n.1, p.74-79, 2014.

VESENTINI, J. W. Realidades e perspectivas do ensino de geografia no Brasil. In: O ensino de geografia no século XXI. Campinas: Papirus, 2004. 